\title{
Teenage pregnancy and its associated factors among teenage females in Farta woreda, Northwest, Ethiopia, 2020: A community-based cross-sectional study
}

\author{
Bekalu G. Kassa ${ }^{1}$, Habtamu G. Belay ${ }^{1}$, Alemu D. Ayele ${ }^{1}$
}

\section{AFFILIATION}

1 Department of Midwifery, College of Health Sciences, Debre Tabor University, Debre Tabor, Ethiopia

CORRESPONDENCE TO

Bekalu G. Kassa. Department of Midwifery, College of Health Sciences, Debre Tabor University, P.O. Box 272, Debre Tabor, Ethiopia. E-mail: bekalugetnet947@gmail.com

\section{KEYWORDS}

teenage pregnancy, Farta woreda, Amhara, Ethiopia

Received: 22 March 2021, Revised: 20 June 2021, Accepted: 20 June 2021

https://doi.org/10.18332/popmed/139190
30.3). Residence (AOR=0.46; 95\% CI: 0.11-0.80), early age at 1 st sexual intercourse $(\mathrm{AOR}=1.68 ; 95 \% \mathrm{CI}: 1.57-4.21)$, not knowing family planning methods $(\mathrm{AOR}=2.14 ; 95 \% \mathrm{CI}$ : 1.54-2.54), not utilizing contraception (AOR $=2.31 ; 95 \% \mathrm{CI}$ : 1.06-4.99) and did not know a place where contraceptive methods are provided (AOR=3.46; 95\% CI: 1.89-11.06) have significant association with teenage pregnancy.

CONCLUSIONS Residence, early age at 1st sexual intercourse, not knowing family planning methods, not utilizing contraception and not being aware of a place where contraceptive methods are provided were associated with teenage pregnancy. The creation of awareness for the timing of safe sexual intercourse, the types and locations where family planning methods are available, and the promotion of family planning use for postponing pregnancy, should be taken into account within family planning.

including discriminatory laws and regulations on the availability of contraceptives based on age or marital status and stigma against health workers. Also, they face obstacles that prohibit contraception from being used and/or used reliably and appropriately, even though adolescents can obtain contraceptives ${ }^{5}$.

Girls between 10 and 19 years of age account for $11 \%$ of births worldwide. Of this 11\%, almost all births, $95 \%$, are in low- to middle-income countries, like Ethiopia ${ }^{6,7}$. Approximately 16 million girls aged $10-19$ years and 2.5 million girls aged $<16$ years give birth annually in developing regions ${ }^{8,9}$. Complications during pregnancy and childbirth are the leading cause of death for girls aged 10-19 years worldwide ${ }^{10}$.

Industrialized and developing countries have distinctly 
different rates of teenage pregnancy. In developed regions, teenage parents appear to be unmarried and adolescent pregnancy is seen as a social problem. Teen parents in developing regions, on the other hand, are often married and the family and community can accept their pregnancy. However, early pregnancy in these cultures can be combined with malnutrition and inadequate health care to cause medical problems ${ }^{11}$. Worldwide, teenagers suffer from early marriage, sexually transmitted infections including HIV/AIDS, female genital mutilation, malnutrition, anemia, infertility, sexual and gender-based abuse, unwanted pregnancy, and illegal abortion ${ }^{12,13}$.

The reviewed literature showed that age, marital status, residency, maternal education, partner education, lack of parent to adolescent communication on sexual and reproductive health issues and inadequate opportunity at community level for positive youth development, illiteracy, age at marriage and contraceptive utilization, have significant association with teenage pregnancy ${ }^{14-17}$.

In Ethiopia, teenage mothers are more likely to experience adverse pregnancy outcomes like high incidence of unwanted pregnancies and incomplete and unsafe/septic abortions. According to the Ethiopian Demographic and Health Survey (EDHS) 2016, 13\% of women aged 10-19 years have begun childbearing. As expected, the proportion of women aged 10 19 years who have begun childbearing rises rapidly with age, from $2 \%$ among women at age of 15 years to $28 \%$ among those aged 19 years. Teenage childbearing is more common in rural than in urban areas ( $15 \%$ vs $5 \%$, respectively) and among women in Amhara (8.3\%) ${ }^{14}$.

Even though different studies were conducted at the national level, there is a scarcity of studies in the study area. Additionally, much of the focus of fertility and use of maternal health services are directed to the general population of reproductive age rather than this specific age group. Hence, we intended to assess the magnitude and the associated factors of teenage pregnancy in the Farta district.

\section{METHODS}

\section{Study design and setting}

A community-based cross-sectional study design was conducted from 15 February 2020 to 24 March 2020 among female adolescents aged 10-19 years in Farta district, south Gondar zone in Amhara region, northwest Ethiopia. Farta district is one of the 15 districts in South Gondar Zone, situated in Amhara National Regional State, Ethiopia and located 660 kilometers northwest from the capital city of Ethiopia, Addis Ababa. The district is subdivided into 31 rural and 2 urban kebeles (smallest administrative units of Ethiopia). Based on the 2015 demographic survey projection, amongst the 276144 population in the woreda, 136221 are females. The current estimate of adolescents aged 10-19 years between 1 February and 1 March 2019, were 18984 . In Farta district there were 10 health centers, 56 health posts and 4 private health clinics ${ }^{18}$.

\section{Participants}

The source population was all female adolescents aged 1019 years in Farta district. The study population was all female adolescents aged 10-19 years in randomly selected kebeles and had been living at least six months in the study area of the selected kebeles.

\section{Inclusion and exclusion criteria}

All women who have lived in the study area for a minimum of 6 months and female teenagers aged 10-19 years were included. Whereas the exclusion criteria were female teenagers aged $<10$ years and $>19$ years, seriously ill, and unable to communicate during the study period.

\section{Variables}

\section{Dependent variable}

Teenage pregnancy was measured by the item: 'Have you ever been pregnant', which was asked of all female respondents regardless of their age. The answer options were: Yes (1) and No (0).

\section{Independent variables}

Sociodemographic variables included age, religion, ethnic group, marital status, education level, occupational status, monthly family income; and history of sexual and reproductive health, age at first sexual intercourse, contraceptive use, age at marriage (early marriage), age at 1st pregnancy, planned pregnancy, perception on teenage pregnancy.

\section{Operational definition}

Teenage pregnancy: pregnancy in teenagers aged 10-19 years confirmed by a healthcare provider ${ }^{13}$.

\section{Sample size determination}

Single population proportion formula was used to determine the sample size. A 95\% confidence interval (CI), a margin of error of $5 \%$ and $28.6 \%$ proportion of teenage pregnancy among females ${ }^{17}$ aged 10-19 years was considered. We used a design effect of 1.5 to avoid the effect of the design that decreases the representativeness of the study. To compensate for non-response, $5 \%$ of the determined sample was added and the final sample size was 343 .

\section{Sampling techniques}

We used the multistage sampling technique to select the sampling unit. First, all kebeles were stratified into urban and rural areas. The district constitutes 31 rural and two urban kebeles. A simple random sampling technique was used to select one out of two urban kebeles and eight out of 31 rural kebeles. Finally, the census was conducted at each selected kebele to register all women aged $10-19$ years and to create a sampling frame. The final calculated sample size was allocated proportionally to each selected kebele after the population size of each selected kebele was identified. 
The starting point from the sampling frame was obtained by using lottery methods, then the study participants were selected from each kebele by using systematic random sampling techniques until the desired sample size was obtained. When the eligible woman was not available in the household, the data collector went to their house repeatedly within the study period, as the household was labelled and mapped before data collection, rather than going to the next home to fulfill the sample size; whereas when there was more than one eligible woman in a household, the interviewed woman was selected via lottery methods.

\section{Data collection procedure and quality assurance}

The data collection tool comprised structured questionnaires that were prepared after a thorough literature review and the local situation of the study area and purpose of the study were considered. Questionnaires were prepared first in English then translated to Amharic, which is the vernacular language of the respondents, by a language expert for ease of understanding by the respondents. Data were collected via face-to-face interview technique. To assure the quality of the data, technical training was given before data collection for data collectors, and pre-testing was conducted on $10 \%$ of a sample size to pilot test the survey tool on kebeles outside the actual data collection site that have characteristics similar to the study population. Data collection was done by 5 trained diploma midwives and was supervised by three BSc midwives. Throughout the data collection period, the supervisor monitored data collection and checked each filled questionnaire for completeness. Finally, the data were cleaned after entry to ensure completeness.

\section{Statistical analysis}

Data were coded, cleaned and entered by Epidata version 3.1 and analyzed using computer database software and exported to the SPSS version 23 statistical software. Descriptive statistics, bivariable and multivariable logistic regression analyses were used to identify associated factors. Variables having $\mathrm{p} \leq 0.2$ in the bivariable analysis were fitted into multiple logistic regression models to control the effect of confounding. Crude and adjusted odds ratios with their 95\% CI were calculated to determine the strength and presence of association. A $\mathrm{p} \leq 0.05$ was considered to declare a level of significance.

\section{RESULTS}

\section{Sociodemographic characteristics of the respondents}

A total of 343 teenagers were interviewed, with a response rate of $100 \%$. There were $297(86.6 \%)$ respondents aged 1519 years with a mean age $16.73 \pm 1.75$ years. Eighty-seven per cent of respondents lived in rural areas. More than half of the respondents (53.1\%) were married, and $84 \%$ of respondents were Orthodox. More than one-third of respondents, 123 (35.9\%), were unable to read and write, and 74 (21.6\%) had attended grade 9 and above. The median monthly family income of respondents was $4000 \pm 2900$ birr (Table 1).

\section{Sexual and reproductive health characteristics of respondents}

One hundred and ninety (55.4\%) respondents had sexual intercourse and 39 (20.5\%) started before 15 years of age. Out of those who had sex, 144 (75.8\%) used contraceptives. More than half of the respondents (53.6\%) had a history of premarital sex. More than one-third (32.2\%) of respondents' age at 1 st pregnancy was less than 18 years. The proportion of teenage pregnancies among respondents in Farta district was $25.4 \%$ (87) (95\% CI: 21.3-30.3). Almost all (93\%) of respondents knew a place where contraceptive methods

\section{Table 1. Sociodemographic characteristics of} respondents in Farta district, south Gondar zone, Northwest Ethiopia, $2020(\mathrm{~N}=343)$

\begin{tabular}{|c|c|c|}
\hline Characteristics & $\mathbf{n}$ & $\%$ \\
\hline \multicolumn{3}{|l|}{ Age (years) } \\
\hline $13-14$ & 46 & 13.4 \\
\hline $15-19$ & 297 & 86.6 \\
\hline \multicolumn{3}{|l|}{ Residence } \\
\hline Urban & 45 & 13.1 \\
\hline Rural & 298 & 86.9 \\
\hline \multicolumn{3}{|l|}{ Marital status } \\
\hline Single & 182 & 53.1 \\
\hline Married & 135 & 39.4 \\
\hline Divorced & 26 & 7.6 \\
\hline \multicolumn{3}{|l|}{ Religion } \\
\hline Orthodox & 288 & 84 \\
\hline Muslim & 48 & 14 \\
\hline Protestant & 7 & 2 \\
\hline \multicolumn{3}{|l|}{ Ethnicity } \\
\hline Amhara & 266 & 77.6 \\
\hline Tigrie & 40 & 10.8 \\
\hline Oromo & 37 & 11.7 \\
\hline \multicolumn{3}{|c|}{ Educational status } \\
\hline Grade $12+$ & 4 & 1.2 \\
\hline Grade $9-12$ & 70 & 20.4 \\
\hline Grade 5-8 & 83 & 24.2 \\
\hline Grade $1-4$ & 63 & 18.4 \\
\hline Illiterate & 123 & 35.9 \\
\hline \multicolumn{3}{|c|}{ Income $(\operatorname{Birr})^{*}(n=303)$} \\
\hline$<1000$ & 48 & 15.8 \\
\hline $1000-5000$ & 194 & 64 \\
\hline$\geq 5000$ & 61 & 20.1 \\
\hline
\end{tabular}

*Ethiopian Birr: 1000 Birr about 23 US\$. 
Table 2. Continued

Table 2. Sexual and reproductive health

characteristics of respondents in Farta district,

Northwest Ethiopia, 2020

\begin{tabular}{|c|c|c|}
\hline Characteristics & $\mathbf{n}$ & $\%$ \\
\hline \multicolumn{3}{|c|}{$\begin{array}{l}\text { Age at 1st sexual intercourse } \\
\text { (years) }(n=190)\end{array}$} \\
\hline $13-14$ & 39 & 20.5 \\
\hline $15-17$ & 84 & 44.2 \\
\hline 18-19 & 67 & 35.3 \\
\hline \multicolumn{3}{|l|}{ Premarital sex } \\
\hline Yes & 184 & 53.6 \\
\hline No & 159 & 46.4 \\
\hline \multicolumn{3}{|c|}{$\begin{array}{l}\text { Age at marriage (years) } \\
(n=161)\end{array}$} \\
\hline$<18$ & 46 & 28.6 \\
\hline$\geq 18$ & 115 & 71.4 \\
\hline \multicolumn{3}{|c|}{$\begin{array}{l}\text { Age at 1st pregnancy (years) } \\
(n=87)\end{array}$} \\
\hline$<18$ & 28 & 32.2 \\
\hline$\geq 18$ & 59 & 67.8 \\
\hline \multicolumn{3}{|c|}{ Do you know about FP? } \\
\hline Yes & 296 & 86.3 \\
\hline No & 47 & 13.7 \\
\hline \multicolumn{3}{|c|}{$\begin{array}{l}\text { Type of FP methods you } \\
\text { know }(n=296)\end{array}$} \\
\hline Pills & 81 & 27.4 \\
\hline Depo-Provera & 84 & 28.4 \\
\hline Condom & 34 & 11.5 \\
\hline Implants & 36 & 12.2 \\
\hline IUD & 33 & 11.1 \\
\hline Other & 28 & 9.5 \\
\hline
\end{tabular}

\begin{tabular}{|c|c|c|}
\hline Characteristics & $\mathbf{n}$ & $\%$ \\
\hline \multicolumn{3}{|c|}{$\begin{array}{l}\text { Do you know where FP } \\
\text { methods are provided? }\end{array}$} \\
\hline Yes & 319 & 93 \\
\hline No & 24 & 7 \\
\hline \multicolumn{3}{|c|}{ Do you ever use FP methods? } \\
\hline Yes & 144 & 74.8 \\
\hline No & 46 & 25.2 \\
\hline \multicolumn{3}{|c|}{$\begin{array}{l}\text { Have you ever been } \\
\text { pregnant? }\end{array}$} \\
\hline Yes & 87 & 25.4 \\
\hline No & 256 & 74.6 \\
\hline \multicolumn{3}{|c|}{$\begin{array}{l}\text { Pregnancy planned and } \\
\text { wanted? }(n=87)\end{array}$} \\
\hline Yes & 49 & 56.3 \\
\hline No & 38 & 43.7 \\
\hline \multicolumn{3}{|c|}{$\begin{array}{l}\text { Reason for unplanned and } \\
\text { unwanted pregnancy }(n=38)\end{array}$} \\
\hline Unsafe sex & 20 & 52.6 \\
\hline Sexual violence & 7 & 18.4 \\
\hline Method failure & 11 & 28.9 \\
\hline
\end{tabular}

FP: family planning.

were provided, and for $38(11.1 \%)$ of respondents the pregnancy was unplanned (Table 2).

\section{Factors associated with teenage pregnancy}

Multivariable logistic regressions revealed that residence, age at first sexual intercourse, knowing about family planning methods, utilization of contraception and knowing

Table 3. Bivariable and multivariable analysis of factors associated with teenage pregnancy in Farta district, south Gondar zone, Northwest Ethiopia, 2020

\begin{tabular}{|c|c|c|c|c|}
\hline \multirow[t]{2}{*}{ Variable } & \multicolumn{2}{|c|}{ Teenage pregnancy } & \multirow[t]{2}{*}{ OR $(95 \% \mathrm{CI})$} & \multirow[t]{2}{*}{ AOR $(95 \% \mathrm{CI})$} \\
\hline & Yes & No & & \\
\hline \multicolumn{5}{|l|}{ Age (years) } \\
\hline $15-19$ & 81 & 216 & $2.5(1.02-6.12) *$ & $0.405(0.148-1.107)$ \\
\hline 13-14 (Ref.) & 6 & 40 & 1 & 1 \\
\hline \multicolumn{5}{|l|}{ Marital status } \\
\hline Single & 47 & 135 & $0.406(0.18-0.94) *$ & $0.933(0.410-2.824)$ \\
\hline Married & 28 & 107 & $0.305(0.127-0.733) *$ & $2.320(0.628-8.576)$ \\
\hline Divorced (Ref.) & 12 & 14 & 1 & 1 \\
\hline \multicolumn{5}{|l|}{ Residence } \\
\hline Urban & 9 & 36 & $0.705(0.325-1.53)$ & $0.464(0.119-0.808) * *$ \\
\hline Rural (Ref.) & 78 & 220 & 1 & 1 \\
\hline
\end{tabular}


Table 3. Continued

\begin{tabular}{|c|c|c|c|c|}
\hline \multirow[t]{2}{*}{ Variable } & \multicolumn{2}{|c|}{ Teenage pregnancy } & \multirow[t]{2}{*}{ OR $(95 \% \mathrm{CI})$} & \multirow[t]{2}{*}{$\operatorname{AOR}(95 \% \mathrm{CI})$} \\
\hline & Yes & No & & \\
\hline \multicolumn{5}{|c|}{ Age at first sexual intercourse (years) } \\
\hline $13-14$ & 7 & 32 & $1.829(0.711-0.804)$ & $1.681(1.571-4.213) *$ \\
\hline $15-17$ & 24 & 60 & $1.554(0.58-4.165)$ & $0.303(0.04-2.273)$ \\
\hline 18-19 (Ref.) & 17 & 50 & 1 & 1 \\
\hline \multicolumn{5}{|c|}{ Did you know about FP method? } \\
\hline Yes (Ref.) & 71 & 225 & 1 & 1 \\
\hline No & 16 & 31 & $1.636(0.846-3.164)$ & $2.140(1.54-2.547) *$ \\
\hline \multicolumn{5}{|c|}{$\begin{array}{l}\text { Did you know where FP methods } \\
\text { are provided? }\end{array}$} \\
\hline Yes (Ref.) & 78 & 241 & 1 & 1 \\
\hline No & 9 & 15 & $1.854(0.781-4.403)$ & $3.469(1.088-11.061) * *$ \\
\hline \multicolumn{5}{|c|}{ Did you ever use FP methods? } \\
\hline No & 35 & 64 & $2.02(1.21-3.37) *$ & $2.305(1.063-4.998) * *$ \\
\hline Yes (Ref.) & 52 & 192 & 1 & 1 \\
\hline
\end{tabular}

AOR: adjusted odds ratio. *Significant on binary analysis. ${ }^{* *}$ Significant on multivariable analysis. Ref.: reference category.

a place where family planning methods are provided, were significantly associated with teenage pregnancy.

Respondents who live in urban areas were less likely to have had a teenage pregnancy compared to those respondents who lived in rural areas (AOR $=0.46$; $95 \% \mathrm{CI}$ : $0.12-0.81$ ). Age between 13 and 14 years at first sexual intercourse was associated with a higher likelihood of teenage pregnancy compared to those who had their first sexual intercourse at an age between 18 and 19 years (AOR=1.68; 95\% CI: 1.57-4.21). Respondents who were not aware of family planning methods were two times more likely to have had a teenage pregnancy $(\mathrm{AOR}=2.14 ; 95 \% \mathrm{CI}$ : 1.54-2.55).

Respondents who were not aware of a place to obtain family planning methods were more likely to have had a teenage pregnancy (AOR=3.47; 95\% CI: 1.09-11.06), while respondents that did not use contraception were more likely to have a teenage pregnancy (AOR=2.31; $95 \% \mathrm{CI}$ : 1.06-4.99) (Table 3).

\section{DISCUSSION}

This cross-sectional study revealed that the overall prevalence of teenage pregnancy in the study area was 25.4\% (95\% CI: 21.3-30.3); which is in line with the crosssectional studies conducted in northeast Ethiopia where the prevalence was $28.6 \%{ }^{17}$. This may be due to the similarity of study design, sociodemographic factors and the study population.

The finding of this study was low compared with the finding from Kampala, Uganda, which found that four in every ten teenagers attending Naguru teenage Centre are pregnant ${ }^{19}$ and that from northwest region of Cameroon $(60.75 \%)^{20}$. This is mainly due to differences in the study population; the previous study was conducted on teenagers, which may significantly increase the prevalence of teenage pregnancy. Also, the finding of this study was lower than that of Kibuku Town, Eastern Uganda, which was $35.8 \%{ }^{21}$. This might be due to the sociocultural, norm and economic differences.

This finding was higher with studies conducted in Latin America $(19.1 \%)^{22}$, Vietnam (4\%) ${ }^{23}$, South Africa $(19.2 \%)^{24}$, 2016 EDHS finding which was $13 \%{ }^{14}$, Assosa general hospital which was $20.4 \%{ }^{25}$, and Arba Minch Town $7.7 \%{ }^{12}$. Sociodemographic and cultural differences may explained the values. On another perspective, this difference may be due to the time gap between studies.

In addition to estimating the prevalence of teenage pregnancy, this study tried to determine factors associated with teenage pregnancy. Teenagers who live in the urban area had a 53.6\% lower occurrence of pregnancy compared to their rural counterparts, which is similar to the study done in northeast Ethiopia ${ }^{17}$. This could be because teenagers from the rural areas have limited access to information, education, accessibility and availability of youth reproductive services especially family planning methods.

Age at first sexual intercourse was another factor associated with teenage pregnancy. Teenagers aged 13-14 years were more likely to become pregnant compared to those aged 18-19 years; which is supported by studies in Assosa Ethiopia ${ }^{25}$ and Brazil ${ }^{26}$.

But the finding of this study was inconsistent with an EDHS report in $2011^{27}$ and systematic reviews from three 
consecutive EDHS reports ${ }^{28}$ that showed that the national median age at first sexual intercourse for women aged 25-49 years is 16.6 years. This study is different to a cross-sectional study conducted in five Vietnamese provinces ${ }^{29}$. While teenagers who did not know about family planning methods were more likely to get pregnant compared to those who were familiar; which is supported by studies in California ${ }^{30}$ and Brazil ${ }^{26}$.

The result of this study also showed that women who did not use contraception were more likely to become pregnant than those who had experience of contraceptives. This finding is similar to the study conducted in Assosa, Ethiopia ${ }^{25}$, Wogedi, Wollo Ethiopia ${ }^{17}$, and South Sudan ${ }^{31}$. This could be explained by the fact that proper utilization of contraception can delay the pregnancy until wanted, and also from the contraception service they obtained information about the best time for a first pregnancy.

Respondents who did not know the place where family planning methods were provided were more prone to a teenage pregnancy compared with those who knew. These finding is supported by a study in $\operatorname{Iran}^{32}$. This findings will provide relevant information for zonal, regional and national health organizations for future planning and designing strategies to decrease teenage pregnancies in the community. Health professionals will also understand the gaps that exist in reproductive issues in teenagers.

\section{Strengths and Limitations}

There are two limitations to this analysis. First, the research results are cross-sectional, which restricts the ability to assess the causal path between independent variables and dependent variables. Second, most importantly, there could be under-reporting of teenage pregnancy by survey participants due to stigma associated with early sexual activity and pregnancy during adolescence. Future studies should overcome these limitations and incorporate quantitative and qualitative studies.

\section{CONCLUSIONS}

The prevalence of teenage pregnancies in the study area was high. Residence, age at first sexual intercourse, not knowing family planning methods, not utilizing contraception and not knowing a place that provides family planning methods, were significantly associated with teenage pregnancy. Creating awareness of the timing of safe sexual practice, family planning methods, places where family planning methods are provided, and promoting family planning utilization to delay pregnancy, are needed.

\section{REFERENCES}

1. World Health Organization. Adolescent pregnancy factsheet: adolescence is a time of opportunity during which a range of actions can be taken to set the stage for healthy adulthood. World Health Organization; 2014. Accessed June 20, 2021. https://apps.who.int/iris/
bitstream/handle/10665/112320/WHO_RHR_14.08_eng. pdf;sequence $=1$

2. Blum RW, Gates WH. Girlhood, Not Motherhood: Preventing Adolescent Pregnancy. United Nations Population Fund; 2015. Accessed June 20, 2021. https://www.unfpa.org/sites/ default/files/pub-pdf/Girlhood_not_motherhood_final_web. pdf

3. Svanemyr J, Chandra-Mouli V, Raj A, Travers E, Sundaram L. Research priorities on ending child marriage and supporting married girls. Reprod Health. 2015;12(1):80. doi:10.1186/s12978-015-0060-5

4. World Health Organization. Global and regional estimates of violence against women: prevalence and health effects of intimate partner violence and non-partner sexual violence. World Health Organization; 2013. Accessed June 20, 2021. https://apps.who.int/iris/ bitstream/handle/10665/85239/9789241564625_eng. pdf?sequence $=1$ \&isAllowed $=y$

5. Laldas J. Teen pregnancy a rising concern. News24. October 17, 2018. Accessed June 20, 2021. https://www.news24. com/news24/SouthAfrica/Local/Stanger-Weekly/teenpregnancy-a-rising-concern-20181010

6. Neal S, Matthews Z, Frost M, Fogstad H, Camacho AV, Laski L. Childbearing in adolescents aged 12-15 years in low resource countries: a neglected issue. New estimates from demographic and household surveys in 42 countries. Acta Obstet Gynecol Scand. 2012;91(9):1114-1118. doi:10.1111/j.1600-0412.2012.01467.x

7. World Health Organization. Global Strategy for Women's, Children's and Adolescents' Health (2016-2030): KEY STATISTICS. Accessed June 20, 2021. https://www.who.int/ life-course/partners/global-strategy/global-strategy-keystatistics-03-11-2017.pdf

8. Prevalence of teenage pregnancy. Wikipedia. Updated June 10, 2021. Accessed June 20, 2021. https://en.wikipedia.org/ wiki/Prevalence_of_teenage_pregnancy

9. Alemayehu T, Haider J, Habte D. Determinants of adolescent fertility in Ethiopia. Ethiop J Health Dev. 2010;24(1):30-38. doi:10.4314/ejhd.v24i1.62942

10. Neema S, Musisi N, Kibombo R. Adolescent Sexual and Reproductive Health in Uganda: A Synthesis of Research Evidence. The Alan Guttmacher Institute; 2004. Occasional Report No. 14. December 2004. Accessed June 20, 2021. https://www.guttmacher.org/sites/default/files/pdfs/ pubs/2004/12/20/or14.pdf

11. Kassa GM, Arowojolu AO, Odukogbe AA, Yalew AW. Prevalence and determinants of adolescent pregnancy in Africa: a systematic review and Meta-analysis. Reprod Health. 2018;15(1):195. doi:10.1186/s12978-018-0640-2

12. Mathewos S, Mekuria A. Teenage Pregnancy and Its Associated Factors among School Adolescents of Arba Minch Town, Southern Ethiopia. Ethiop J Health Sci. 2018;28(3):287-298. doi:10.4314/ejhs.v28i3.6

13. Ayele BG, Gebregzabher TG, Hailu TT, Assefa BA. Determinants of teenage pregnancy in Degua Tembien 
District, Tigray, Northern Ethiopia: A community-based case-control study. PLoS One. 2018;13(7):e0200898. doi:10.1371/journal.pone.0200898

14. Central Statistical Agency, ICF International. ETHIOPIA Demographic and Health Survey 2016: Key Indicators Report. CSA, ICF International; 2016. Accessed June 20, 2021. https://evaw-global-database.unwomen.org/-/ media/files/un\%20women/vaw/vaw\%20survey/1\%20 ethiopia\%20dhs\%202016.pdf?vs=4831

15. Pati RN, Tekie S. BIOCULTURAL DYNAMICS OF TEENAGE PREGNANCIES IN ETHIOPIA:MEDICO ANTHROPOLOGICAL APPRAISAL. International Journal of Social Sciences and Management. 2016;3(1):68-77. doi:10.3126/ijssm.v3i1.14368

16. Naziru MT. DETERMINANTS OF ADOLESCENT PREGNANCY: A CASE-CONTROL STUDY IN THE AMENFI WEST DISTRICT, GHANA. Master's thesis. Kwame Nkrumah University of Science and Technology; 2016. Accessed June 20, 2021. http://ir.knust.edu.gh/xmlui/bitstream/ handle/123456789/10150/MOHAMMED\%20TANKO\%20 NAZIRU.pdf?sequence $=1$

17. Habitu YA, Yalew A, Bisetegn TA. Prevalence and Factors Associated with Teenage Pregnancy, Northeast Ethiopia, 2017: A Cross-Sectional Study. J Pregnancy. 2018;2018:1714527. doi:10.1155/2018/1714527

18. Mihretie GN, Yenealem Beyene F, Getnet Kassa B, Degu Ayele A, Muche Liyeh T, Minuye Birihane B. Determinants of short birth interval among women in South Gondar, Ethiopia: community-based unmatched case-control study. Arch Public Health. 2021;79(1):47. doi:10.1186/s13690-021-00567-7

19. Kolawole AK, Fatimah A. Prevalence of teenage pregnancy and its associated factors among teenagers attending Naguru teenage centre Kampala, Uganda. Paper presented at: 5 th International Congress on Primary Healthcare \& Family Medicine Primary Healthcare \& Family Medicine; November 29-30, 2017; Madrid, Spain. Accessed June 20, 2021. https:// www.imedpub.com/conference-abstracts-files/prevalenceof-teenage-pregnancy-and-its-associated-factors.pdf

20. Donatus L, Sama DJ, Tsoka-Gwegweni JM, Cumber SN. Factors associated with adolescent school girl's pregnancy in Kumbo East Health District North West region Cameroon. Pan Afr Med J. 2018;31:138. doi:10.11604/pamj.2018.31.138.16888

21. Manzi F, Ogwang J, Akankwatsa A, et al. Factors Associated with Teenage Pregnancy and its Effects in Kibuku Town Council, Kibuku District, Eastern Uganda: A Cross Sectional Study. Prim Health Care. 2018;8(2):298. doi:10.4172/2167-1079.1000298

22. Dongarwar D, Salihu HM. Influence of Sexual and Reproductive

ACKNOWLEDGEMENTS

We thank Debre Tabor University for giving ethical clearance. We thank Farta Woreda Health Office for permitting us to conduct the study and providing the necessary preliminary information. We would also like to extend our appreciation to the study participants, supervisors, data collectors and health extension workers.
Health Literacy on Single and Recurrent Adolescent Pregnancy in Latin America. J Pediatr Adolesc Gynecol. 2019;32(5):506513. doi:10.1016/j.jpag.2019.06.003

23. Nguyen H, Shiu C, Farber N. Prevalence and Factors Associated with Teen Pregnancy in Vietnam: Results from Two National Surveys. Societies (Basel). 2016;6(2):17. doi:10.3390/soc6020017

24. Mchunu G, Peltzer K, Tutshana B, Seutlwadi L. Adolescent pregnancy and associated factors in South African youth. Afr Health Sci. 2012;12(4):426-434. doi:10.4314/ahs.v12i4.5

25. Beyene A, Muhiye A, Getachew Y, et al. ASSESSMENT OF THE MAGNITUDE OF TEENAGE PREGNANCY AND ITS ASSOCIATED FACTORS AMONG TEENAGE FEMALES VISITING ASSOSA GENERAL HOSPITAL. Ethiop Med J. 2015;53(suppl 2):25-37. Accessed June 20, 2021. https:// www.emjema.org/index.php/EMJ/article/view/131/pdf_18

26. Brito MB, Alves FSS, Souza MQ, Requião SR. Low Level of Knowledge of Contraceptive Methods among Pregnant Teens in Brazil. J Pediatr Adolesc Gynecol. 2018;31(3):281-284. doi:10.1016/j.jpag.2017.12.008

27. Central Statistical Agency, ICF International. Ethiopia Demographic and Health Survey 2011. Central Statistical Agency, ICF International; 2012. Accessed June 20, 2021. https://dhsprogram.com/pubs/pdf/FR255/FR255.pdf

28. Reda AA, Lindstrom D. Recent trends in the timing of first sex and marriage among young women in Ethiopia. Etude Popul Afr. 2014;28(2 Suppl):1157-1170. doi:10.11564/28-0-564

29. Ngoc Do H, Ngoc Nguyen D, Quynh Thi Nguyen H, et al. Patterns of Risky Sexual Behaviors and Associated Factors among Youths and Adolescents in Vietnam. Int J Environ Res Public Health. 2020;17(6):1903. doi:10.3390/ijerph17061903

30. Guzzo KB, Hayford SR. Adolescent Reproductive and Contraceptive Knowledge and Attitudes and Adult Contraceptive Behavior. Matern Child Health J. 2018;22(1):32-40. doi:10.1007/s10995-017-2351-7

31. Vincent G, Alemu FM. Factors contributing to, and effects of, teenage pregnancy in Juba. South Sudan Medical Journal. 2016;9(2):28-31. Accessed June 20, 2021. http://www. southsudanmedicaljournal.com/assets/files/Journals/ vol_9_iss_2_may_16/SSMJ_9_2_Teenage_pregnancy_in_Juba. pdf

32. Mardi A, Ebadi A, Shahbazi S, Esmaelzade Saeieh S, Behboodi Moghadam Z. Factors influencing the use of contraceptives through the lens of teenage women: a qualitative study in Iran. BMC Public Health. 2018;18(1):202. doi:10.1186/s12889-018-5116-3

\section{CONFLICTS OF INTEREST}

The authors have completed and submitted the ICMJE Form for Disclosure of Potential Conflicts of Interest and none was reported.

FUNDING

There was no source of funding for this research. 
from the corresponding author on a reasonable request.

ETHICAL APPROVAL AND INFORMED CONSENT

Ethical clearance was obtained from the ethical review committee of Bahir Dar University College of Medicine and Health Science (IRB reference number: CHS/IRB 03-008). Both written and verbal informed consent was obtained from each study participant. Written informed consent was obtained from parents/guardians for participants younger than 16 years.

DATA AVAILABILITY

The datasets collected and analyzed for the current study are available

\section{AUTHORS' CONTRIBUTIONS}

BG: conceived and designed the study, conducted statistical analysis and results interpretation; $\mathrm{BG}, \mathrm{HG}$ and $\mathrm{AD}$ : prepared and edited the manuscript, assisted with data analysis and interpretation. All authors read and approved the manuscript.

PROVENANCE AND PEER REVIEW

Not commissioned; externally peer reviewed. 